Article

\title{
An Amylase-Like Protein, AmyD, Is the Major Negative Regulator for $\alpha$-Glucan Synthesis in Aspergillus nidulans during the Asexual Life Cycle
}

\author{
Xiaoxiao $\mathrm{He}^{1, *}$, Shengnan $\mathrm{Li}^{2}$ and Susan Kaminskyj ${ }^{3}$ \\ 1 Key Laboratory of Molecular Epigenetics, Ministry of Education, Institute of Genetics and Cytology, \\ Northeast Normal University, Changchun 130024, Jilin, China \\ 2 Jilin Institute of Biology, Changchun 130012, Jilin, China; lishengnan8435@hotmail.com \\ 3 Department of Biology, University of Saskatchewan, 112 Science Place, Saskatoon, SK S7N 5E2, Canada; \\ susan.kaminskyj@usask.ca \\ * Correspondence: hexx100@nenu.edu.cn; Tel.: +86-431-8509-9769; Fax: +86-431-8509-8126
}

Academic Editor: Vaclav Vetvicka

Received: 11 February 2017; Accepted: 22 March 2017; Published: 27 March 2017

\begin{abstract}
Glucan affects fungal cell-cell interactions and is important for the virulence of pathogenic fungi. Interfering with production of $\alpha$-glucan could help to prevent fungal infection. In our previous study, we reported that an amylase-like protein, AmyD, could repress $\alpha$-glucan accumulation in Aspergillus nidulans. However, the underlying molecular mechanism was not clear. Here, we examined the localization of AmyD and found it was a membrane-associated protein. We studied AmyD function in $\alpha$-glucan degradation, as well as with other predicted amylase-like proteins and three annotated $\alpha$-glucanases. AmyC and AmyE share a substantial sequence identity with AmyD, however, neither affects $\alpha$-glucan synthesis. In contrast, AgnB and MutA (but not AgnE) are functional $\alpha$-glucanases that also repress $\alpha$-glucan accumulation. Nevertheless, the functions of AmyD and these glucanases were independent from each other. The dynamics of $\alpha$-glucan accumulation showed different patterns between the AmyD overexpression strain and the $\alpha$-glucanase overexpression strains, suggesting AmyD may not be involved in the $\alpha$-glucan degradation process. These results suggest the function of AmyD is to directly suppress $\alpha$-glucan synthesis, but not to facilitate its degradation.
\end{abstract}

Keywords: AmyD; $\alpha$-glucan; A. nidulans; cell wall; fungal virulence

\section{Introduction}

$\alpha-1,3-$-Glucan (hereafter, $\alpha$-glucan) and $\beta-1,3 / 1,6$-glucan (hereafter, $\beta$-glucan) are major cell wall components for many filamentous fungi, as well as for many yeasts [1]. However, they have very different impacts on fungal cells. $\beta$-glucan is essential for fungal cell survival, at least for species of Aspergillus and Candida [2,3], hence, $\beta$-glucan synthase inhibitors (echinocandins) are used clinically to treat systemic aspergillosis and candidiasis [4]. In contrast, $\alpha$-glucan has been found to be important for the morphology of Schizosaccharomyces pombe [5], particularly for cell integrity at cytokinesis [6]. For other fungal species, $\alpha$-glucan synthase deleted strains cause minor or no phenotypic change [7-10]. Nevertheless, accumulated evidence has suggested $\alpha$-glucan has a role in host-pathogen interaction [11-13], which is important for successful pathogenesis. Thus, treatments that could eliminate fungal $\alpha$-glucan might be able to prevent fungal infection. Unfortunately, to our knowledge, no drug has yet been developed that targets $\alpha$-glucan synthase. As an alternative strategy to blocking the synthesis of $\alpha$-glucan, we could potentially degrade $\alpha$-glucan from fungal cell walls to achieve the same purpose. 
$\alpha$-1,3-Glucanase (hereafter, $\alpha$-glucanase) expressed by fungal cells can recycle $\alpha$-glucan from their cell walls. In S. pombe, $\alpha$-glucanase (SpAgn1p) was shown to have an endo-catalytic hydrolysis ability on $\alpha$-glucan (hydrolyzing $\alpha$-glucan into pentasaccharides), and was thereby important for successful cell division [14]. Paracoccidioides brasiliensis $\alpha$-glucanase (PbAgn1p) had comparable activity [15]. In Trichoderma species, two $\alpha$-glucanases have been characterized, and these were suggested to have antifungal effects because their expression was highly induced under antagonistic conditions [16,17]. Together this is strong evidence that $\alpha$-glucanase has the potential to eliminate $\alpha$-glucan from fungal cell walls. Consistent with this, a strain of transgenic rice plants that expressed a bacterial $\alpha$-glucanase was more resistant to Magnaporthe oryzae [12]. Therefore, degrading $\alpha$-glucan from fungal cell walls is a possible way to prevent fungal infection, and characterization of glucanase-like proteins will provide additional useful information about this major but enigmatic wall carbohydrate.

In our previous study, we reported that an amylase-like protein (AmyD) repressed $\alpha$-glucan synthesis in A. nidulans [10]. Amylase-like proteins with similar effects were also seen in S. pombe [18] and A. niger [19]. These data suggest some amylase-like proteins may have the same potential as $\alpha$-glucanase to eliminate $\alpha$-glucan from fungal cell walls. To explore this, we studied the function of AmyD along with two other amylase-like proteins and three $\alpha$-glucanases in the $\alpha$-glucan degradation process. We found that AmyD localized at the cell membrane and was the only amylase-like protein in A. nidulans that could repress $\alpha$-glucan accumulation. In addition, AmyD function was independent from that of $\alpha$-glucanase. All functional $\alpha$-glucanases maintained low expression levels in the A. nidulans asexual life cycle. Thus, AmyD is the major negative regulator for $\alpha$-glucan accumulation in A. nidulans during the asexual life cycle, and may have a potential to prevent fungal infection.

\section{Results}

\subsection{AmyD Mainly Localizes at the Cell Membrane}

In our previous work, we reported that AmyD repressed $\alpha$-glucan synthesis, and so we hypothesized that AmyD might work together with one or more $\alpha-1,3$-glucanases to degrade $\alpha$-glucan [10]. In order to understand the mechanism of AmyD as an $\alpha$ glucanase, it is important to determine its localization. However, due to hindrance from the AmyD protein and the GPI-anchor site, we did not get a visible signal when the green fluorescent protein (GFP) was tagged after the signal peptide (between the 26th and 27th amino acids) or after the GPI-anchor site. To solve these problems, we replaced the amylase domain of AmyD (from the 63rd to the 507th amino acid) by a GFP (for details of the strain construction and verification, see Figure $1 \mathrm{~A}, \mathrm{~B}$ ). The N-terminal signal peptide and C-terminal GPI-anchor site of AmyD were maintained, which were the elements that determined AmyD localization. The same strategy has been reported to solve the localization issue of other GPI-anchored proteins [20,21]. The GFP signal for this strain (chimera-AmyD-GFP) showed strong association with septa (Figure 1C) and patchy localization with the cell membrane (Figure 1D), which was consistent with the localization of a GPI-anchor protein. Therefore, AmyD may be involved in $\alpha$-glucan degradation based on its plasma-membrane localization. 


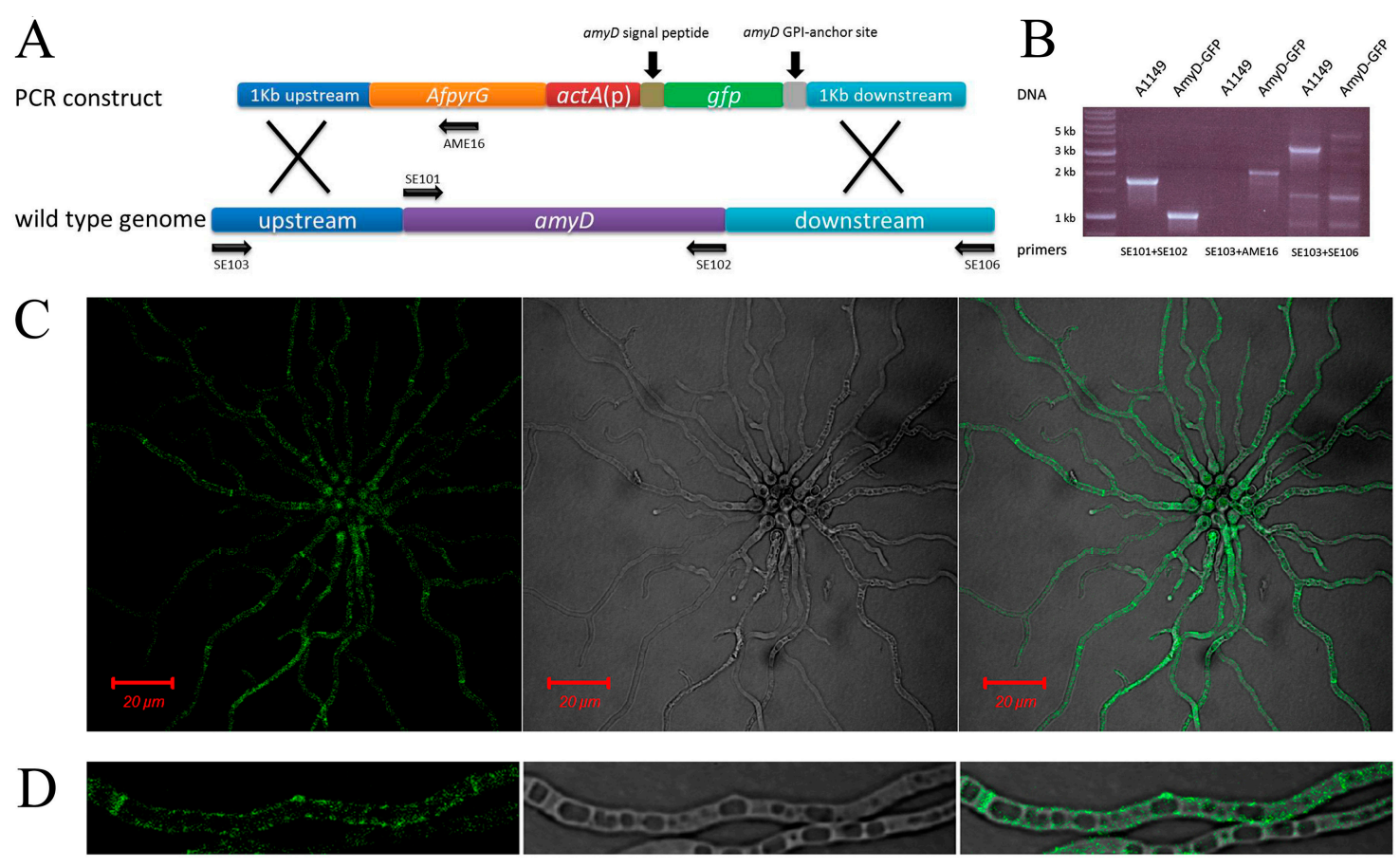

Figure 1. Localization of AmyD associates with cell membrane; (A) Strategy of chimera-AmyD-GFP strain construction. The amylase-like domain of AmyD was replaced by a GFP, whereas the localization determining elements of AmyD were maintained. The localization of AmyD corresponded to a chimera-GFP signal; (B) PCR verification of AmyD-GFP strain. Primers targeting sites were labeled in (A). PCR using SE101 + SE102 primers confirmed the replacement of amyD by $g f p$. PCR using SE103 + AME16 and SE103 + SE106 primers confirmed the integration of the construct at the designed place. No ectopic insertion was found in the AmyD-GFP genome; (C) the GFP signal was examined using a Zeiss META501 confocal epifluorescence microscope at $63 \times$ NA 1.2 or $25 \times$ N.A. 1.0 objective lens. Confocal imaging used $488 \mathrm{~nm}$ excitation with emission controlled by a BP $505-530 \mathrm{~nm}$ filter; and (D) a magnified hypha image showed the GFP signal strongly associated with septa and the cell membrane.

\subsection{AmyC and AmyE Do Not Affect $\alpha$-Glucan Accumulation}

In the $A$. nidulans genome, there are two putative/annotated amylase-like proteins, AmyC (encoded by ANID4507) and AmyE (encoded by ANID6324) that share high sequence similarity with AmyD. Like AmyD, both are predicted to have an N-terminal signal peptide and C-terminal GPI-anchor site [22]. Their overall amino acid sequence identities to AmyD are 59\% (AmyC) and 45\% (AmyE), respectively (Figure S1), suggesting they could have conserved functions with AmyD.

To study their functions, we first examined their expression levels to see when we could expect to detect their activities. Samples were grown in shaken liquid medium and in static liquid medium for $14 \mathrm{~h}$ and $24 \mathrm{~h}$ respectively. In shaken liquid medium, $A$. nidulans grows vegetatively (hyphal elongation only) but does not undergo colony development. In static liquid medium, $A$. nidulans undergoes its complete asexual life cycle. Conidiophores with conidia were seen when we collected the static samples at $24 \mathrm{~h}$. Unlike $a m y D$ that had a general high basal expression [10], we found $a m y C$ and $a m y E$ maintained low expression levels throughout the $A$. nidulans asexual life cycle (Table 1$)$. This conclusion was based on high $\mathrm{Ct}$ values of $a m y C$ and $a m y E$ in $\mathrm{qPCR}$ (data not shown). Therefore, their activities are not expected in asexual life stages. 
Table 1. Time-course expression study.

\begin{tabular}{|c|c|c|c|c|c|}
\hline \multirow[b]{2}{*}{ genes } & \multicolumn{2}{|c|}{ Shaken Growth } & \multicolumn{2}{|c|}{ Static Growth } & \multirow{2}{*}{$\frac{\text { Overexpression by } a c t A(p)}{14 \mathrm{~h}}$} \\
\hline & $14 \mathrm{~h}$ & $24 \mathrm{~h}$ & $14 \mathrm{~h}$ & $24 \mathrm{~h}$ & \\
\hline amyc & 1 & $1.44 \pm 0.44$ & $1.28 \pm 0.28$ & $18.84 \pm 6.36$ & $794.13 \pm 190.28$ \\
\hline amyE & 1 & $1.72 \pm 0.71$ & $1.93 \pm 0.49$ & $27.82 \pm 9.79$ & $484.82 \pm 140.61$ \\
\hline agn B & 1 & $2.16 \pm 0.63$ & $2.39 \pm 0.83$ & $11.71 \pm 3.93$ & $871.00 \pm 191.59$ \\
\hline $\operatorname{agnE}$ & 1 & $1.92 \pm 0.57$ & $1.59 \pm 0.53$ & $274.90 \pm 85.55$ & $1268.84 \pm 292.38$ \\
\hline mutA & 1 & $2.97 \pm 0.89$ & $2.31 \pm 0.96$ & $6.96 \pm 1.99$ & $1753.59 \pm 654.97$ \\
\hline
\end{tabular}

We overexpressed amyC and amyE to examine their effects on $\alpha$-glucan. An actin promoter $(\operatorname{act} A(\mathrm{p}))$ from $A$. nidulans was used to overexpress these genes as we previously used for $a m y D$ [10]. The $\operatorname{act} A(\mathrm{p})-a m y C$ and $a c t A(\mathrm{p})-a m y E$ strains had no obvious phenotypic change compared to the wild-type reference strain A1149, when tested on solid medium, or when grown in shaken liquid medium with respect to the colony size (Figure 2A,B). In contrast, the $a c t A(\mathrm{p})$-amyD strain formed many tiny colonies in shaken liquid culture (Figure 2B). This suggests that AmyC and AmyE may not have the same function as AmyD. Our qPCR results showed amyC and amyE were each overexpressed by several hundred-fold when regulated by act $A(\mathrm{p})$, confirming their low expression under native promoters (Table 1). However, the $\alpha$-glucan content in $a c t A(\mathrm{p})$-amyC and $\operatorname{act} A(\mathrm{p})$-amyE was comparable to the wild-type cells (Figure 2C), unlike act $A(\mathrm{p})$-amyD (Figure 2C). So far, AmyD is the only reported amylase-like protein that has a repressive effect on $\alpha$-glucan accumulation in $A$. nidulans.

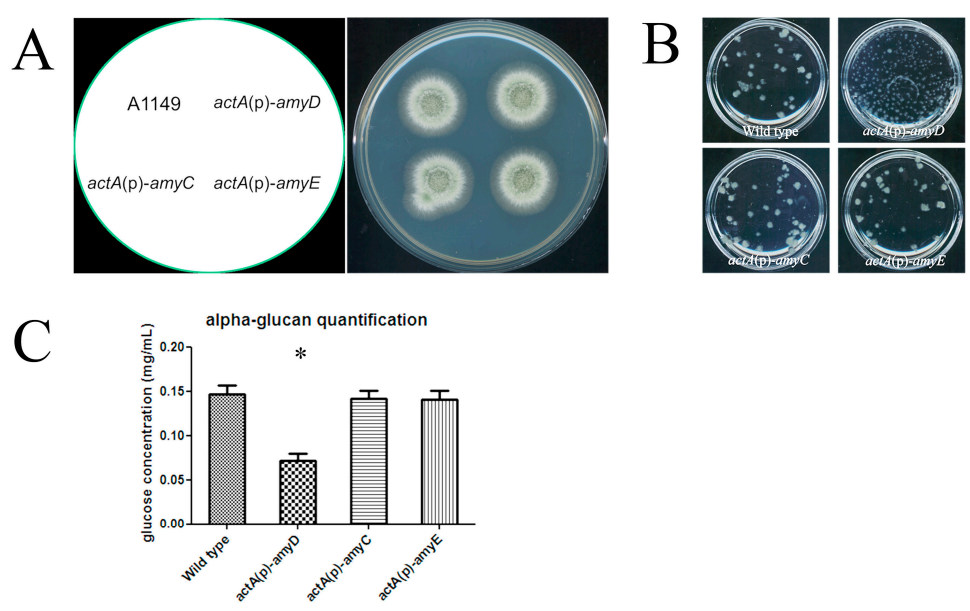

Figure 2. Overexpression of amyC and amyE does not affect significantly $\alpha$-glucan accumulation. (A) $10^{5}$ freshly harvested conidia of each strain were inoculated on complete medium and the plates were incubated at $30{ }^{\circ} \mathrm{C}$ for $48 \mathrm{~h}$. All constructed strains showed the wild type colony phenotype on solid medium; $(\mathbf{B})$ a large number $\left(5 \times 10^{7}\right)$ of freshly harvested conidia were inoculated in flask with $20 \mathrm{~mL}$ complete medium, then the flask was incubated at $30{ }^{\circ} \mathrm{C}, 150 \mathrm{rpm}$ overnight. Only act $A(\mathrm{p})$-amyD formed tiny colonies; $(\mathbf{C})$ A large number $\left(2 \times 10^{7}\right)$ of spores of each strain were inoculated in $100 \mathrm{~mL}$ complete medium. Samples were grown in flasks at $30{ }^{\circ} \mathrm{C}$ with $150 \mathrm{rpm}$ for $24 \mathrm{~h}$. $\alpha$-glucan was extracted from $1 \mathrm{mg}$ dry cell wall, and then digested to glucose and quantified by an anthrone assay. Results represent the mean of three independent quantification tests with duplicates each time \pm standard deviation. The data for each strain were compared with wild type (column 1 ) individually by Mann Whitney $U$ test. Significant difference $(p<0.05)$ is indicated by asterisks.

\subsection{MutA, as Well as AgnB, but Not AgnE, Can Repress $\alpha$-Glucan Accumulation}

In order to verify whether AmyD could facilitate $\alpha$-glucan degradation, we needed to find a functional $\alpha$-glucanase. MutA (encoded by ANID7349) is the only characterized $\alpha$-glucanase in A. nidulans. However, its expression has only been studied for the sexual life cycle [23]. Two more $\alpha$-glucanase encoding genes, agnB (ANID3790) and agnE (ANID1604), have also been annotated in the 
A. nidulans genome [22]. Therefore, AgnB and AgnE were chosen as our study candidates and MutA was included as a positive control.

A time-course expression study showed that both agnB and mutA had very low expression throughout $A$. nidulans asexual life cycle (Table 1), whereas expression of agnE was highly induced during conidiation (Table 1). When the $\alpha$-glucanases were individually deleted, this change had no impact on colony phenotypes or $\alpha$-glucan content (Figure $3 \mathrm{~A}-\mathrm{C}$ ), as expected due to their low expression levels in vegetative growth. When the $\alpha$-glucanases were individually overexpressed by $\operatorname{act} A(\mathrm{p})$, each had a many hundred-fold increase in expression level (Table 1), but only the overexpression of AgnB and MutA led to a lower $\alpha$-glucan content (Figure 3D). Therefore, AgnB and MutA are the functional $\alpha$-glucanases in our test. For colonies grown on solid medium, the $\operatorname{act} A(\mathrm{p})-a g n B$ strain had a pale colony color (Figure $3 \mathrm{E}$ ), even though quantification of conidiation was unchanged (Table S1), showing that the color change was not due to the conidia number. We expect that the color difference could be due to a defect in conidia pigment formation somehow related to the overexpression of agnB. Intriguingly, both $a c t A(\mathrm{p})$-agn $B$ and $\operatorname{act} A(\mathrm{p})-m u t A$ behaved the same as wild-type in shaken liquid medium (Figure $3 \mathrm{~F}$ ), unlike act $A(\mathrm{p})$-amyD that formed tiny colonies (Figure 2B). We also deleted AgnB and MutA together, just in case they might compensate for each other when individually deleted. However, the double deletion strain still had no impact on $\alpha$-glucan content (Figure 3C).

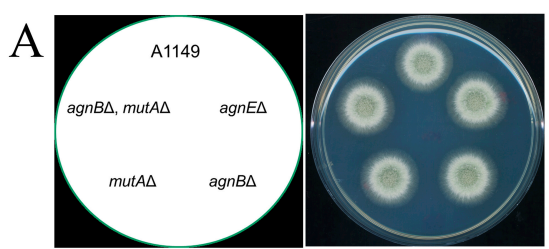

C

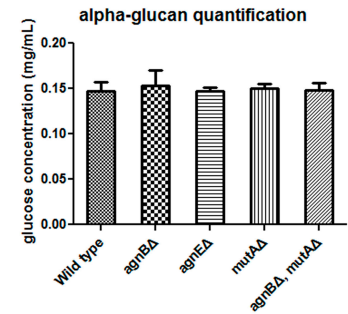

$\mathrm{E}$

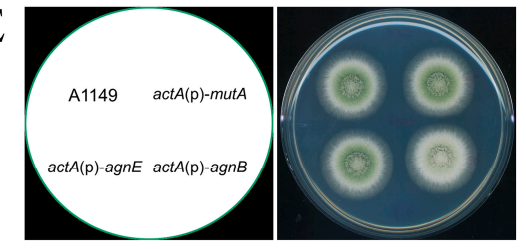

B

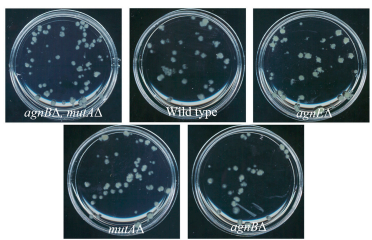

$\mathrm{D}$

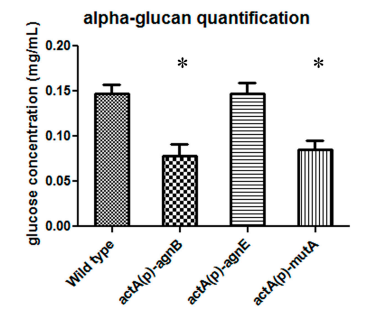

$\mathrm{F}$

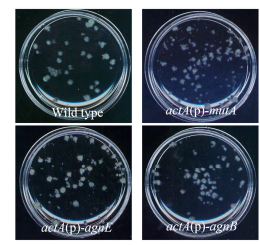

Figure 3. AgnB and MutA are functional $\alpha$-glucanases. (A) Freshly harvested conidia $\left(10^{5}\right)$ of each strain were inoculated on complete medium and the plates were incubated at $30{ }^{\circ} \mathrm{C}$ for $48 \mathrm{~h}$. All constructed strains showed the wild-type colony phenotype on solid medium; (B) freshly harvested conidia $\left(5 \times 10^{7}\right)$ were inoculated in a flask with $20 \mathrm{~mL}$ complete medium, then the flask was incubated at $30{ }^{\circ} \mathrm{C}, 150 \mathrm{rpm}$ overnight. All strains behaved the same as the wild-type; $(\mathbf{C}, \mathbf{D})$ spores of the indicated strain $\left(2 \times 10^{7}\right)$ were inoculated in $100 \mathrm{~mL}$ complete medium. Samples were grown in flasks at $30^{\circ} \mathrm{C}$ with $150 \mathrm{rpm}$ for $24 \mathrm{~h}$. $\alpha$-glucan was extracted from $1 \mathrm{mg}$ of dry cell wall, and then digested to glucose and quantified using an anthrone assay [24]. Results represent the mean of three independent quantification tests with duplicates each time \pm standard deviation. The data for each strain were compared with the wild-type (column 1 ) individually by a Mann Whitney $U$ test. Significant difference $(p<0.05)$ was indicated by asterisks; $(\mathbf{E})$ conidia of each strain were prepared and inoculated as in $(\mathbf{A})$. Only act $A(\mathrm{p})$-agnB showed pigment deficiency; and (F) all strains behaved the same as the wild-type in shaken liquid medium. Growth condition was the same as described in (B). 


\subsection{Functions of AgnB and MutA Are Independent from AmyD}

Our results showed that overexpressed AgnB, MutA, and AmyD all had similar repressive effects on $\alpha$-glucan content (Figures 2C and 3D). Considering they each have a signal peptide and a GPI-anchor site [20], we hypothesized that AmyD may work together with either or both $\alpha$-glucanases to degrade $\alpha$-glucan [10]. If our hypothesis was correct, the repressive effects on $\alpha$-glucan content from AgnB and MutA should be abolished or reduced when AmyD was deleted. To verify this, we generated $(a c t A(\mathrm{p})-a g n B, a m y D \Delta)$ and $(a c t A(\mathrm{p})-m u t A, a m y D \Delta)$ strains. We found these two strains had wild-type phenotypes on solid medium and in shaken liquid medium (Figure $4 \mathrm{~A}, \mathrm{~B}$ ). The pigment defect in $a c t A(\mathrm{p})-a g n B$ was recovered with the deletion of $a m y D$ (Figures $3 \mathrm{E}$ and $4 \mathrm{~A}$ ). However, both strains still showed low $\alpha$-glucan content similar to act $A(\mathrm{p})$-agnB and act $A(\mathrm{p})-m u t A$ (Figures $3 \mathrm{D}$ and $4 \mathrm{C}$ ), indicating the effects of AgnB and MutA were still present. Therefore, the functions of AgnB and MutA appear to be independent from AmyD.
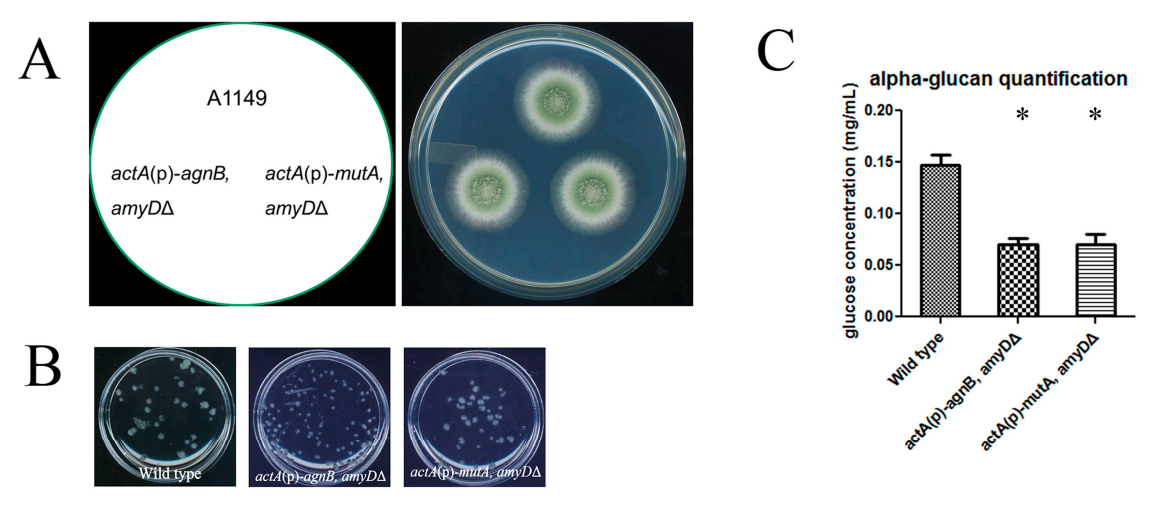

Figure 4. The absence of AmyD cannot suppress the increased $\alpha$-glucan production of agnB- or $m u t A$-overexpression strains. (A) All constructed strains showed the wild-type colony phenotype on solid medium; (B) all strains behaved the same as the wild-type; and (C) $\alpha$-glucan was extracted from $1 \mathrm{mg}$ of dry cell wall, and then digested to glucose and quantified using an anthrone assay. Results represent the mean of three independent quantification tests with duplicates each time \pm standard deviation. The data for each strain were compared with wild type (column 1) individually by a Mann Whitney $U$ test. Significant difference $(p<0.05)$ was indicated by asterisks.

\subsection{Dynamics of $\alpha$-Glucan Accumulation Affects Colony Formation in Liquid Medium and Drug Sensitivity}

It was interesting to see that $a c t A(\mathrm{p})$-agnB, $\operatorname{act} A(\mathrm{p})-m u t A$, and $\operatorname{act} A(\mathrm{p})-\operatorname{amy} D$ strains had similar $\alpha$-glucan content (Figures $2 \mathrm{C}$ and $3 \mathrm{D}$ ), but behaved differently in shaken liquid medium (compare Figure 2B with Figure 3F). We thought this might be because of how $\alpha$-glucan accumulated in these strains. In all of our previous quantification experiments, we collected the fungal cell samples at $24 \mathrm{~h}$ post-inoculation. In contrast, visualization of colonies in shaken liquid had typically been done earlier, usually around $16 \mathrm{~h}$ post-inoculation. Thus, we also collected additional samples at $16 \mathrm{~h}$ and $20 \mathrm{~h}$ post-inoculation to examine the dynamics of $\alpha$-glucan accumulation in cell walls. Results showed very different patterns of $\alpha$-glucan accumulation in these strains (Figure 5A). In wild-type, $\alpha$-glucan content increased from $16 \mathrm{~h}$ to $24 \mathrm{~h}$. In act $A(\mathrm{p})$-amyD, the trend to increasing $\alpha$-glucan was maintained, but at each time point the concentration of $\alpha$-glucan was only about $50 \%$ of the wild-type. However, in $\operatorname{act} A(\mathrm{p})$-agnB and $\operatorname{act} A(\mathrm{p})-m u t A, \alpha$-glucan content showed a decreasing trend from $16 \mathrm{~h}$ to $24 \mathrm{~h}$. We also noticed that at $16 \mathrm{~h}$ the $\alpha$-glucan content in wild-type, act $A(\mathrm{p})$-agnB, and $\operatorname{act} A(\mathrm{p})$-mut $A$ was very similar, whereas the $\alpha$-glucan content in $a c t A(\mathrm{p})$-amy $D$ was much lower.

In our previous work, we found that $\alpha$-glucan content was correlated with sensitivity to Calcofluor White (CFW) [10]. We wondered if this change was also correlated with $\alpha$-glucan accumulation dynamics. We tested all strains on $50 \mu \mathrm{g} / \mathrm{mL}$ CFW. Only act $A(\mathrm{p})$-amyD showed delayed germination and/or slower growth, whereas all other strains maintained the same growth ability (Figure 5B). 

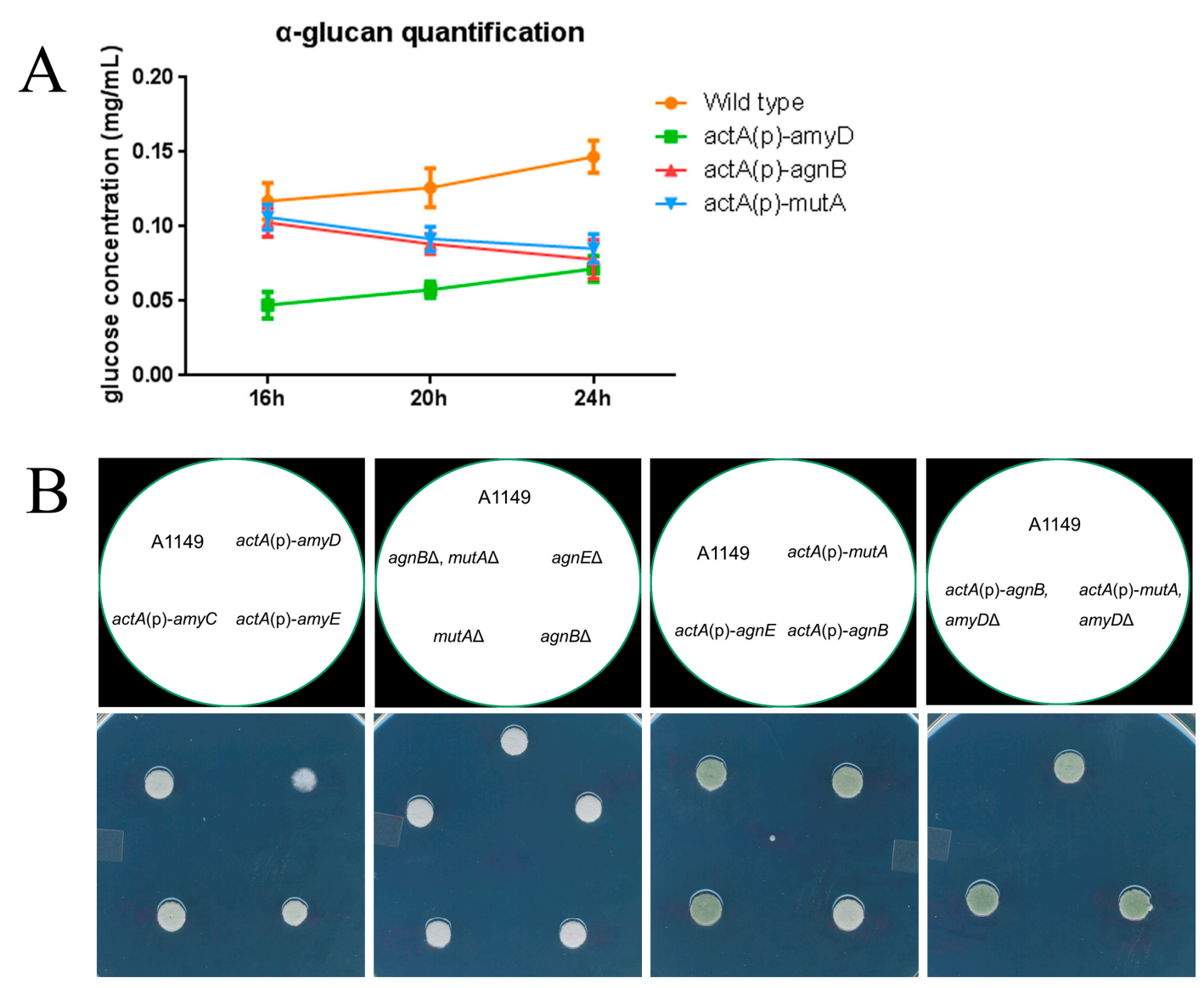

Figure 5. Dynamics of $\alpha$-glucan accumulation and its impact on CFW sensitivity. (A) Dynamics of $\alpha$-glucan accumulation in each strain with time. $2 \times 10^{7}$ spores of each strain were inoculated in $100 \mathrm{~mL}$ complete medium. Samples were grown in flasks at $30^{\circ} \mathrm{C}$ with $150 \mathrm{rpm}$ for $16 \mathrm{~h}, 20 \mathrm{~h}$, and $24 \mathrm{~h}$, respectively. $\alpha$-glucan was extracted from $1 \mathrm{mg}$ of dry cell wall, and then digested to glucose and quantified by an anthrone assay. Wild-type and $\operatorname{act} A(\mathrm{p})$-amy $D$ showed the same increasing trend from $16 \mathrm{~h}$ to $24 \mathrm{~h}$, except the glucose concentration in $a c t A(\mathrm{p})$-amy $D$ was much lower than that of the wild-type at each time point. The $\operatorname{act} A(\mathrm{p})-\operatorname{agn} B$ and $\operatorname{act} A(\mathrm{p})-m u t A$ had the same decreasing trend from $16 \mathrm{~h}$ to $24 \mathrm{~h}$; (B) freshly harvested conidia $\left(10^{5}\right)$ of each strain were inoculated on $50 \mu \mathrm{g} / \mathrm{mL}$ CFW plates and the plates were incubated at $30^{\circ} \mathrm{C}$ for $48 \mathrm{~h}$. Only act $A(\mathrm{p})$-amyD showed delayed germination and growth.

\section{Discussion}

In our previous study, we found AmyD repressed $\alpha$-glucan accumulation in A. nidulans [10]. To investigate the underlying mechanism, we extended our work to other $\alpha$-glucan metabolism-related genes to further understand the function of AmyD.

\subsection{AmyD Is the Major Negative Regulator of $\alpha$-Glucan Accumulation in the A. nidulans Asexual Life Cycle}

Both $a m y C$ and $a m y E$ share high sequence similarity with $a m y D$, however our results showed they did not affect $\alpha$-glucan accumulation. They also had no impact on starch digestion when tested on starch-only medium (unpublished data), so their functions remain unclear. So far, AmyD is the only reported amylase-like protein that can repress $\alpha$-glucan accumulation in A. nidulans. From our results, the $\alpha$-glucanases, AgnB and MutA showed similar repressive effects as AmyD when overexpressed (Figure 3D). However, each maintained a very low expression level in the A. nidulans asexual life cycle (Table 1), especially when compared to the expression level of amyD at each stage. This also explained why deletion of AgnB and MutA had no impact on $\alpha$-glucan accumulation (Figure 3C), 
but deletion of AmyD did [10]. Altogether, we conclude AmyD is the major negative regulator of $\alpha$-glucan accumulation during A. nidulans asexual life cycle. However, we could not rule out that AgnB and MutA may have particular roles in certain types of cells during colony development, which needs further investigation.

\subsection{Functions of $\alpha$-Glucanases and AmyD Are Independent from Each Other}

Our results confirmed MutA as a functional $\alpha$-glucanase and also revealed that AgnB, but not AgnE, had the same effect as AmyD to repress $\alpha$-glucan accumulation. However, the low expression level of $m u t A$ and agnB in the $A$. nidulans asexual life cycle (Table 1 ) suggested that $\alpha$-glucan degradation is not active during these stages. This is consistent with why even the mut $A$ and agn $B$ double-deletion strains maintained the same $\alpha$-glucan content as the wild-type. This could also explain why the most prominent anti- $\alpha$-glucan antibody-staining signal was from the older hyphal regions [10], because $\alpha$-glucan was not recycled during the asexual life cycle. With this in mind, we think the function of AmyD is not based on $\alpha$-glucanase.

On the other hand, amyD had a relatively high expression level during A. nidulans asexual development [10]. It is still possible the function of $\alpha$-glucanase depends on AmyD. However, when amy $D$ was deleted from $a c t A(\mathrm{p})$-agnB and $a c t A(\mathrm{p})-m u t A$, the repressive effects on $\alpha$-glucan from AgnB and MutA were maintained (Figure $4 \mathrm{C}$ ). Therefore, the functions of glucanases are independent from AmyD. Evidence from other $\alpha$-glucanase characterization work also showed that $\alpha$-glucanase is functional by itself [14-16]. In addition, we noticed that, when AgnB or MutA was overexpressed in an AmyD $\Delta$ background, the effect from AmyD deletion was abolished (compare data in [10] with Figures $3 \mathrm{D}$ and $4 \mathrm{C}$ ). Thus, we interpret this as $\alpha$-glucanases being superior in regulating $\alpha$-glucan content in the cell wall.

In our study, we did find that the deletion of $a m y D$ in an $a c t A(p)$-agn $B$ strain reversed the pigment formation defect (compare Figure 3E with Figure 4A), which was a specific phenotypic change in $\operatorname{act} A(\mathrm{p})$-agnB. Otherwise, we have never found that low $\alpha$-glucan content led to a pigment defect. Therefore, we think this phenotypic change does not relate to $\alpha$-glucan content.

\section{3. $\alpha$-Glucan Content in Early Life Stage Is Critical for Colony Formation in Shaken Liquid as Well as Drug Sensitivity}

Our dynamics study showed that the $\alpha$-glucan accumulation processes in $\operatorname{act} A(\mathrm{p})$-agn $B$ and $a c t A(\mathrm{p})-m u t A$ were unlike $a c t A(\mathrm{p})-a m y D$ (Figure $5 \mathrm{~A}$ ). Although these colonies had similar $\alpha$-glucan content after $24 \mathrm{~h}$ growth, the $\alpha$-glucan content at $16 \mathrm{~h}$ and $20 \mathrm{~h}$ was different. Especially at $16 \mathrm{~h}$, the $\alpha$-glucan content in $a c t A(\mathrm{p})$-agnB and act $A(\mathrm{p})$-mut $A$ was almost the same as the wild-type, whereas in $a c t A(\mathrm{p})$-amyD the $\alpha$-glucan level was only half that of the wild-type. This could explain why $\operatorname{act} A(\mathrm{p})-\operatorname{agn} B$ and $\operatorname{act} A(\mathrm{p})-m u t A$ formed the regular size colonies as wild type (Figure 3F), because colony formation in shaken liquid was already complete at $16 \mathrm{~h}$. Even though the $\alpha$-glucan content decreased in these two strains at later time, the formed colonies were unable to disassemble. The same principle also explained why $a c t A(\mathrm{p})-a g n B$ and $a c t A(\mathrm{p})-m u t A$ maintained the same drug sensitivity as the wild-type (Figure 4B). When $A$. nidulans was stressed by CFW, spore germination was delayed. However, the higher $\alpha$-glucan content in the early life stage enabled the $\operatorname{act} A(\mathrm{p})$-agn $B$ and $\operatorname{act} A(\mathrm{p})$-mut $A$ strains to form colonies on solid medium faster than act $A(\mathrm{p})$-amy $D$.

Why the effects of AgnB and MutA started later than AmyD still needs further study, however, it is clear the mechanism of AmyD is different from $\alpha$-glucanase. According to the different $\alpha$-glucan accumulation patterns (Figure $5 \mathrm{~A}$ ), it is more likely that AmyD directly represses $\alpha$-glucan synthesis rather than facilitating $\alpha$-glucan degradation. One possible reason is that AmyD may affect the major $\alpha$-glucan synthase (AgsB) expression. However, the qPCR analysis revealed no significant difference of agsB expression in $a m y D \Delta$ and $\operatorname{act} A(\mathrm{p})$-amyD strains compared to A1149 (Table S2).

AgtA, the homologue of AmyD in A. niger, has been enzymatically characterized [19]. These results showed AgtA had very low starch hydrolysis ability but served as a glucanotransferase on 
$\alpha-1,4$-glucosidic linkages. The amino acid sequence identity between AmyD and AgtA is $70 \%$, so it is highly likely AmyD will have a similar function as AgtA, but this will need enzymatic study to confirm and is beyond the scope of our current work. Further study on the mechanism of AmyD will also require establishing an in vitro $\alpha$-glucan synthesis system to find out how AmyD prevents $\alpha$-glucan accumulation. Nevertheless, considering the repressive effect of AmyD on $\alpha$-glucan accumulation, AmyD may potentially prevent fungal infection. For instance, $\alpha$-glucan was shown to be maintained at a minimal level in the conidia of $M$. oryzae, and was required during pathogenesis [12]. Therefore, effective $\alpha$-glucan synthesis is important during this process and this newly-synthesized $\alpha$-glucan is believed to function as a mask to protect the fungal cells from host immune recognition [11,12]. If the host cell could express AmyD to suppress $\alpha$-glucan synthesis, the infection may fail due to the detection of host immune system, as Fujikawa and colleagues showed [12].

In summary, AmyD is the only reported amylase-like protein that can repress $\alpha$-glucan accumulation in A. nidulans, and it is also the major negative regulator during the asexual life cycle. The dynamics study showed the effect of AmyD started earlier than $\alpha$-glucanase, and the mechanism of AmyD was different and independent from $\alpha$-glucanase. These data suggested AmyD may not serve for $\alpha$-glucan degradation, but instead may directly repress $\alpha$-glucan synthesis at the protein level.

\section{Materials and Methods}

\subsection{Strains, Plasmids, and Medium}

All strains in this study were constructed in A. nidulans A1149. The A1149 strain was also the wild-type control for all assays in this paper. Strains used in this study are listed in Table S3. Primers and plasmids are listed in Table S4. Strategies for gene deletion and confirmation methods were described by Szewczyk et al. [25] and El-Ganiny et al. [26]. Briefly, a targeted replacement construct was constructed by fusion PCR including $1 \mathrm{~kb}$ upstream, a selectable marker, and $1 \mathrm{~kb}$ downstream (details see Figure $\mathrm{S} 2 \mathrm{~A}$ ). This construct was transformed to A1149 protoplasts. A. fumigatus pyrG and pyro $A$ were used as selectable markers (details for each strain see Figure S2B). The strategy for promoter exchange was previously described in [10]. For promoter exchange, the transformation construct was $1 \mathrm{~kb}$ upstream of the target, the selectable marker, $a c t A(\mathrm{p})$ and $1 \mathrm{~kb}$ of the target gene from $5^{\prime}$ end (Figure S2A). The actA promoter was amplified from A1149 genomic DNA and the sequence was given in Figure S3. Again, details for each construction see Figure S2B. PCR confirmation of each constructed strain is shown in Figure S4.The sequence of each overexpression strain was confirmed by DNA sequencing, and only a clone lacking mutations was used for further study.

For generation of a strain expressing an chimera-AmyD-GFP strain, a construct containing all following elements: $1 \mathrm{~kb}$ upstream of $a m y D, A f p y r G, a c t A(\mathrm{p})$, amyD signal peptide sequence, gfp (no stop codon) and amyD GPI-anchor site sequence, and $1 \mathrm{~kb}$ downstream of $a m y D$, was generated and transformed to A1149 protoplasts. For details of strain construction and verification see Figure 2A,B.

All strains were grown on complete medium (CM: $1 \%$ glucose, $0.2 \%$ peptone, $0.1 \%$ yeast extract, $0.1 \%$ casamino acids, $50 \mathrm{~mL} 20 \times$ nitrate salts, $1 \mathrm{~mL}$ trace elements, $1 \mathrm{~mL}$ vitamin solution, $\mathrm{pH}$ 6.5) or minimal medium (MM: $1 \%$ glucose, $50 \mathrm{~mL} 20 \times$ nitrate salts, $1 \mathrm{~mL}$ trace elements, $0.001 \%$ thiamine, $\mathrm{pH}$ 6.5) supplemented with nutrition solution as required. Trace elements $\left(2.2 \mathrm{~g} \mathrm{ZnSO} \cdot 7 \mathrm{H}_{2} \mathrm{O}\right.$, $1.1 \mathrm{~g} \mathrm{H}_{3} \mathrm{BO}_{3}, 0.5 \mathrm{~g} \mathrm{MnCl}_{2} \cdot 4 \mathrm{H}_{2} \mathrm{O}, 0.5 \mathrm{~g} \mathrm{FeSO}_{4} \cdot 7 \mathrm{H}_{2} \mathrm{O}, 0.17 \mathrm{~g} \mathrm{CoCl}_{2} \cdot 6 \mathrm{H}_{2} \mathrm{O}, 0.16 \mathrm{~g} \mathrm{CuSO}_{4} \cdot 5 \mathrm{H}_{2} \mathrm{O}, 0.15 \mathrm{~g}$ $\mathrm{Na}_{2} \mathrm{MoO}_{4} \cdot 2 \mathrm{H}_{2} \mathrm{O}$, and $5 \mathrm{~g} \mathrm{Na} \mathrm{EDTA}_{4}$ in $100 \mathrm{~mL}$ water, pH adjusted to 6.5 by $\mathrm{KOH}$ pellets), vitamin solution (100 mg each of biotin, pyridoxin, thiamine, riboflavin, PABA ( $p$-aminobenzoic acid), and nicotinic acid per $100 \mathrm{~mL}$ water), nitrate salt, and all nutrition stocks are described in Kaminskyj [27]. For transformation medium, $1 \mathrm{M}$ sucrose was added to $\mathrm{MM}$ as osmoticum. All strains were grown at $30{ }^{\circ} \mathrm{C}$, unless otherwise mentioned. 


\subsection{Quantification of Conidiation}

Molten CM agar (1.5 mL) was added to each well in a 24-well plate and seeded with $10^{5}$ conidia after solidification. Plates were incubated for $4 \mathrm{~d}$, then $1 \mathrm{~mL}$ ultra-pure water from Barnstead ${ }^{\mathrm{TM}}$ Nanopure $^{\mathrm{TM}}$ system was used to collect conidia from each well. Conidia were quantified by hemocytometer.

\section{3. $\alpha$-Glucan Quantification}

The method was adapted from Momany et al. [28] and Marion et al. [29], as described in [10]. Briefly, $2 \times 10^{7}$ conidia were grown at $30^{\circ} \mathrm{C}$ in $100 \mathrm{~mL}$ liquid CM, shaken at $150 \mathrm{rpm}$ for $24 \mathrm{~h}$ (or the indicated time). Colonies were collected by filtration and washed with $0.5 \mathrm{M} \mathrm{NaCl}$. Cells were frozen at $-80^{\circ} \mathrm{C}$ for $2-4 \mathrm{~h}$, then broken in disruption buffer (DB: $20 \mathrm{mM}$ Tris, $50 \mathrm{mM}$ EDTA, $\mathrm{pH}$ 8.0) using a Virsonic Ultrasonic Cell Disrupter, until hyphal ghosts formed. Cell walls were separated by centrifugation at $3500 \times g$ for $10 \mathrm{~min}$. The pellet containing the cell wall fraction was washed in DB with stirring for $4 \mathrm{~h}$ at $4{ }^{\circ} \mathrm{C}$ followed by a wash with sterile ultrapure water under the same conditions, pelleted again, and lyophilized. Dry cell wall samples were weighed, then suspended in $1 \mathrm{M} \mathrm{NaOH}$ at $0.5 \mathrm{mg} \cdot \mathrm{mL}^{-1}$. Alkaline extraction was performed overnight at $37^{\circ} \mathrm{C}$. Then $2 \mathrm{~mL}$ of alkaline-soluble fraction (containing $1 \mathrm{mg}$ cell wall) was used for the following process. The alkali was neutralized by acetic acid until $\mathrm{pH}$ 5.5. $\alpha$-Glucan was collected by centrifugation at $12,000 \times g$ for $10 \mathrm{~min}$, and then washed twice in ultrapure water. Finally, $\alpha$-glucan was hydrolyzed by $2 \mathrm{~mL} 3 \mathrm{M} \mathrm{H}_{2} \mathrm{SO}_{4}$, at $100{ }^{\circ} \mathrm{C}$ for $1 \mathrm{~h}$. Glucose content (mainly from $\alpha$-glucan in the alkali-soluble fraction) was quantified using the anthrone assay [30]. Briefly, $100 \mu \mathrm{L}$ of $\alpha$-glucan hydrolysis solution was added to $1 \mathrm{~mL}$ of anthrone solution $\left(2 \mathrm{mg} / \mathrm{mL}\right.$ in concentrated $\left.\mathrm{H}_{2} \mathrm{SO}_{4}\right)$. Then the mixture was boiled in water for $10 \mathrm{~min}$ with immediate cool on ice. OD630 was measured for each sample. All experiments were repeated three times with duplicates each time.

\subsection{RT-PCR and $q P C R$}

For the time-course expression study, $2 \times 10^{7}$ conidia were inoculated in liquid $\mathrm{CM}$ and incubated at $30{ }^{\circ} \mathrm{C}$ with or without shaking at $150 \mathrm{rpm}$. Colonies were collected at $14 \mathrm{~h}$ and $24 \mathrm{~h}$ for each group. For the static incubation, only the colonies on the liquid surface were collected. Colonies were immediately frozen in liquid nitrogen, and lyophilized.

For the overexpression study, $2 \times 10^{7}$ conidia were inoculated in liquid $\mathrm{CM}$ and incubated at $30{ }^{\circ} \mathrm{C}$ with shaking at $150 \mathrm{rpm}$ for $14 \mathrm{~h}$. Colonies were collected by filtration, immediately frozen in liquid nitrogen, then lyophilized.

Total RNA was extracted using an RNeasy plant kit (Qiagen, Hilden, Germany) following the manufacturer's instructions. RNA concentration was measured using a Nanodrop ${ }^{\circledR}$ (Wilmington, $\mathrm{DE}, \mathrm{USA}$ ), then diluted to $500 \mathrm{ng} \cdot \mu \mathrm{L}^{-1}$. Genomic DNA elimination and reverse transcription used a QuaniTect reverse transcription kit (Qiagen) following the manufacturer instructions.

Quantitative real time PCR (qPCR) was performed in 96-well optical plates in an iQ5 real-time PCR detection system (Bio-Rad, Hercules, CA, USA). Gene expression was assayed in total volume of $20 \mu \mathrm{L}$ per reaction containing cDNA at an appropriate dilution and SYBR green fluorescein (Qiagen). A no-template control was used for each pair of primers. Histone was used as a reference gene [24]. Primers for qPCR are listed in Table S4.

The qPCR amplification used the following conditions: $95^{\circ} \mathrm{C} / 15 \mathrm{~min}$ for one cycle, $95^{\circ} \mathrm{C} / 15 \mathrm{~s}$, $55{ }^{\circ} \mathrm{C} / 40 \mathrm{~s}$ and $72{ }^{\circ} \mathrm{C} / 30 \mathrm{~s}$ for 40 cycles and final extension cycle of $72{ }^{\circ} \mathrm{C} / 2 \mathrm{~min}$. Melting curve analysis was done as follows: $15 \mathrm{~s}$ at $65^{\circ} \mathrm{C}$ with an increase of $0.5^{\circ} \mathrm{C}$ each cycle to $95^{\circ} \mathrm{C}$. The relative expression was normalized to histone and calculated using the $\Delta \Delta C_{t}$ method [31]. Three independent experiments with triplicates were performed for each reaction. 


\subsection{Drug Sensitivity Test}

Calcofluor White (American Cyanamid Company, West Paterson, NJ, USA) was prepared as a stock at $10 \mathrm{mg} \cdot \mathrm{mL}^{-1}$ in $25 \mathrm{mM} \mathrm{KOH} \mathrm{[32].} \mathrm{The} \mathrm{stock} \mathrm{solution} \mathrm{was} \mathrm{sterilized} \mathrm{by} \mathrm{filtration.} \mathrm{For} \mathrm{testing,}$ CFW stock solution was added to $\mathrm{CM}$ agar cooled to $55-60^{\circ} \mathrm{C}$. Then, $10^{5}$ conidia of each strain were inoculated on the plate after solidification. Plates were incubated for $48 \mathrm{~h}$ at $30^{\circ} \mathrm{C}$.

\subsection{Confocal Imaging}

For GFP signal imaging, conidia were grown on dialysis tubing at $30^{\circ} \mathrm{C}$ for $16 \mathrm{~h}$. Samples were examined using a Zeiss META501 confocal epifluorescence microscope at 63 N.A. $1.2 \times$ or $25 \times$ N.A. 1.0 objective lens. Confocal imaging used $488 \mathrm{~nm}$ excitation with emission controlled by a BP $505-530 \mathrm{~nm}$ filter.

\subsection{Statistical Analysis}

All $\alpha$-glucan quantification analyses were performed in three independent tests with duplicates each time. Histograms were created by Graphpad Prism 6 (GraphPad Software, La Jolla, CA, USA). Statistical analysis used a Mann Whitney $U$ test.

\section{Conclusions}

Data from this study showed AmyD is a major repressive effector for $\alpha$-glucan accumulation. The working mechanism of AmyD is totally different from $\alpha$-glucanase. Therefore, AmyD should directly suppress $\alpha$-glucan synthesis.

Supplementary Materials: Supplementary materials can be found at www.mdpi.com/1422-0067/18/4/695/s1.

Acknowledgments: We thank Peta Bonham-Smith lab (Department of Biology, University of Saskatchewan) for access to qPCR. Susan G. W. Kaminskyj was supported by the Natural Science and Engineering Council of Canada Discovery Grant program. Xiaoxiao He was supported by a Graduate Teaching Fellowship from the University of Saskatchewan (UofS), Youth Fund from Jilin Provincial Science and Technology Department (20152520031JH), and the University S\&T Innovation Platform of Jilin Province for Economic Fungi (\#2014B-1).

Author Contributions: This work was designed by Xiaoxiao He and Susan G. W. Kaminskyj. All experiments were performed by Xiaoxiao He and Shengnan Li. The manuscript was written and revised by Xiaoxiao He and Susan G. W. Kaminskyj.

Conflicts of Interest: The authors declare no conflict of interest.

\section{References}

1. Latge, J.P. Tasting the Fungal Cell Wall. Cell. Microbiol. 2010, 12, 863-872. [CrossRef] [PubMed]

2. Douglas, C.M.; D’Ippolito, J.A.; Shei, G.J.; Meinz, M.; Onishi, J.; Marrinan, J.A.; Li, W.; Abruzzo, G.K.; Flattery, A.; Bartizal, K.; et al. Identification of the FKS1 Gene of Candida albicans as the Essential Target of 1,3- $\beta$-D-Glucan Synthase Inhibitors. Antimicrob. Agents Chemother. 1997, 41, 2471-2479. [PubMed]

3. Firon, A.; Beauvais, A.; Latge, J.P.; Couve, E.; Grosjean-Cournoyer, M.C.; D’Enfert, C. Characterization of Essential Genes by Parasexual Genetics in the Human Fungal Pathogen Aspergillus fumigatus: Impact of Genomic Rearrangements Associated with Electroporation of DNA. Genetics 2002, 161, 1077-1087. [PubMed]

4. Denning, D.W. Echinocandin Antifungal Drugs. Lancet 2003, 362, 1142-1151. [CrossRef]

5. Hochstenbach, F.; Klis, F.M.; van den Ende, H.; van Donselaar, E.; Peters, P.J.; Klausner, R.D. Identification of a Putative $\alpha$-Glucan Synthase Essential for Cell Wall Construction and Morphogenesis in Fission Yeast. Proc. Natl. Acad. Sci. USA 1998, 95, 9161-9166. [CrossRef] [PubMed]

6. Cortés, J.C.; Sato, M.; Munoz, J.; Moreno, M.B.; Clemente-Ramos, J.A.; Ramos, M.; Okada, H.; Osumi, M.; Duran, A.; Ribas, J.C. Fission Yeast Ags1 Confers the Essential Septum Strength Needed for Safe Gradual Cell Abscission. J. Cell Biol. 2012, 198, 637-656. [CrossRef] [PubMed]

7. Rappleye, C.A.; Engle, J.T.; Goldman, W.E. RNA Interference in Histoplasma capsulatum Demonstrates a Role for $\alpha-(1,3)-G l u c a n$ in Virulence. Mol. Microbiol. 2004, 53, 153-165. [CrossRef] [PubMed] 
8. Henry, C.; Latge, J.P.; Beauvais, A. $\alpha 1,3$ Glucans are Dispensable in Aspergillus fumigatus. Eukaryot. Cell 2012, 11, 26-29. [CrossRef] [PubMed]

9. Yoshimi, A.; Sano, M.; Inaba, A.; Kokubun, Y.; Fujioka, T.; Mizutani, O.; Hagiwara, D.; Fujikawa, T.; Nishimura, M.; Yano, S.; et al. Functional Analysis of the $\alpha-1,3$-Glucan Synthase Genes ags $A$ and ags $B$ in Aspergillus nidulans: AgsB is the Major $\alpha-1,3-G l u c a n$ Synthase in this Fungus. PLoS ONE 2013, 8, e54893. [CrossRef] [PubMed]

10. He, X.; Li, S.; Kaminskyj, S.G. Characterization of Aspergillus nidulans $\alpha$-Glucan Synthesis: Roles for Two Synthases and Two Amylases. Mol. Microbiol. 2014, 91, 579-595. [CrossRef] [PubMed]

11. Rappleye, C.A.; Eissenberg, L.G.; Goldman, W.E. Histoplasma capsulatum $\alpha-(1,3)$-Glucan Blocks Innate Immune Recognition by the $\beta$-Glucan Receptor. Proc. Natl. Acad. Sci. USA 2007, 104, 1366-1370. [CrossRef] [PubMed]

12. Fujikawa, T.; Sakaguchi, A.; Nishizawa, Y.; Kouzai, Y.; Minami, E.; Yano, S.; Koga, H.; Meshi, T.; Nishimura, M. Surface $\alpha-1,3$-Glucan Facilitates Fungal Stealth Infection by Interfering with Innate Immunity in Plants. PLoS Pathog. 2012, 8, e1002882. [CrossRef] [PubMed]

13. Beauvais, A.; Bozza, S.; Kniemeyer, O.; Formosa, C.; Balloy, V.; Henry, C.; Roberson, R.W.; Dague, E.; Chignard, M.; Brakhage, A.A.; et al. Deletion of the $\alpha-(1,3)$-Glucan Synthase Genes Induces a Restructuring of the Conidial Cell Wall Responsible for the Avirulence of Aspergillus fumigatus. PLoS Pathog. 2013, 9, e1003716. [CrossRef]

14. Dekker, N.; Speijer, D.; Grun, C.H.; van den Berg, M.; de Haan, A.; Hochstenbach, F. Role of the $\alpha$-Glucanase Agn1p in Fission-Yeast Cell Separation. Mol. Biol. Cell 2004, 15, 3903-3914. [CrossRef] [PubMed]

15. Villalobos-Duno, H.; San-Blas, G.; Paulinkevicius, M.; Sanchez-Martin, Y.; Nino-Vega, G. Biochemical Characterization of Paracoccidioides brasiliensis $\alpha-1,3-$ Glucanase Agn1p, and its Functionality by Heterologous Expression in Schizosaccharomyces Pombe. PLoS ONE 2013, 8, e66853. [CrossRef] [PubMed]

16. Ait-Lahsen, H.; Soler, A.; Rey, M.; de La Cruz, J.; Monte, E.; Llobell, A. An Antifungal Exo- $\alpha-1,3-G l u c a n a s e$ (AGN13.1) from the Biocontrol Fungus Trichoderma harzianum. Appl. Environ. Microbiol. 2001, 67, 5833-5839. [CrossRef] [PubMed]

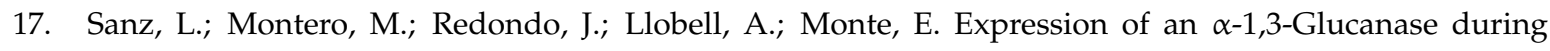
Mycoparasitic Interaction of Trichoderma asperellum. FEBS J. 2005, 272, 493-499. [CrossRef] [PubMed]

18. Morita, T.; Tanaka, N.; Hosomi, A.; Giga-Hama, Y.; Takegawa, K. An $\alpha$-Amylase Homologue, aah3, Encodes a GPI-Anchored Membrane Protein Required for Cell Wall Integrity and Morphogenesis in Schizosaccharomyces pombe. Biosci. Biotechnol. Biochem. 2006, 70, 1454-1463. [CrossRef] [PubMed]

19. Van der Kaaij, R.M.; Yuan, X.L.; Franken, A.; Ram, A.F.; Punt, P.J.; van der Maarel, M.J.; Dijkhuizen, L. Two Novel, Putatively Cell Wall-Associated and Glycosylphosphatidylinositol-Anchored $\alpha$-Glucanotransferase Enzymes of Aspergillus niger. Eukaryot. Cell 2007, 6, 1178-1188. [CrossRef] [PubMed]

20. Kondoh, G.; Gao, X.H.; Nakano, Y.; Koike, H.; Yamada, S.; Okabe, M.; Takeda, J. Tissue-Inherent Fate of GPI Revealed by GPI-Anchored GFP Transgenesis. FEBS Lett. 1999, 458, 299-303. [CrossRef]

21. Hiscox, S.; Hallett, M.B.; Morgan, B.P.; van den Berg, C.W. GPI-Anchored GFP Signals Ca2+ but is Homogeneously Distributed on the Cell Surface. Biochem. Biophys. Res. Commun. 2002, 293, 714-721. [CrossRef]

22. De Groot, P.W.; Brandt, B.W.; Horiuchi, H.; Ram, A.F.; de Koster, C.G.; Klis, F.M. Comprehensive Genomic Analysis of Cell Wall Genes in Aspergillus nidulans. Fungal Genet. Biol. 2009, 46 (Suppl. S1), 72-81. [CrossRef]

23. Wei, H.; Scherer, M.; Singh, A.; Liese, R.; Fischer, R. Aspergillus nidulans $\alpha-1,3$ Glucanase (Mutanase), mutA, is Expressed during Sexual Development and Mobilizes Mutan. Fungal Genet. Biol. 2001, 34, 217-227. [CrossRef] [PubMed]

24. Fujioka, T.; Mizutani, O.; Furukawa, K.; Sato, N.; Yoshimi, A.; Yamagata, Y.; Nakajima, T.; Abe, K. MpkA-Dependent and -Independent Cell Wall Integrity Signaling in Aspergillus nidulans. Eukaryot. Cell 2007, 6, 1497-1510. [CrossRef] [PubMed]

25. Szewczyk, E.; Nayak, T.; Oakley, C.E.; Edgerton, H.; Xiong, Y.; Taheri-Talesh, N.; Osmani, S.A.; Oakley, B.R. Fusion PCR and Gene Targeting in Aspergillus nidulans. Nat. Protoc. 2006, 1, 3111-3120. [CrossRef] [PubMed]

26. El-Ganiny, A.M.; Sanders, D.A.; Kaminskyj, S.G. Aspergillus nidulans UDP-Galactopyranose Mutase, Encoded by ugmA Plays Key Roles in Colony Growth, Hyphal Morphogenesis, and Conidiation. Fungal Genet. Biol. 2008, 45, 1533-1542. [CrossRef] [PubMed] 
27. Kaminskyj, S.G.W. Fundamentals of Growth, Storage, Genetics and Microscopy of Aspergillus nidulans. Fungal Genet. Newsl. 2001, 48, 25-31. [CrossRef]

28. Momany, M.; Lindsey, R.; Hill, T.W.; Richardson, E.A.; Momany, C.; Pedreira, M.; Guest, G.M.; Fisher, J.F.; Hessler, R.B.; Roberts, K.A. The Aspergillus fumigatus Cell Wall is Organized in Domains that are Remodelled during Polarity Establishment. Microbiology 2004, 150, 3261-3268. [CrossRef] [PubMed]

29. Marion, C.L.; Rappleye, C.A.; Engle, J.T.; Goldman, W.E. An $\alpha-(1,4)$-Amylase is Essential for $\alpha-(1,3)-G l u c a n$ Production and Virulence in Histoplasma capsulatum. Mol. Microbiol. 2006, 62, 970-983. [CrossRef] [PubMed]

30. Ashwell, G. Colorimetric analysis of sugars. Methods Enzymol. 1957, II, 73-103.

31. Livak, K.J.; Schmittgen, T.D. Analysis of Relative Gene Expression Data using Real-Time Quantitative PCR and the $2^{-\Delta \Delta C t}$ Method. Methods 2001, 25, 402-408. [CrossRef] [PubMed]

32. Hill, T.W.; Loprete, D.M.; Momany, M.; Ha, Y.; Harsch, L.M.; Livesay, J.A.; Mirchandani, A.; Murdock, J.J.; Vaughan, M.J.; Watt, M.B. Isolation of Cell Wall Mutants in Aspergillus nidulans by Screening for Hypersensitivity to Calcofluor White. Mycologia 2006, 98, 399-409. [CrossRef] [PubMed]

(C) 2017 by the authors. Licensee MDPI, Basel, Switzerland. This article is an open access article distributed under the terms and conditions of the Creative Commons Attribution (CC BY) license (http:/ / creativecommons.org/licenses/by/4.0/). 